signed the petition permitting the formation of this subsection) have been asked to serve on committees, as a result of their expressed desire to be of assistance: Barbara Anderson, San Francisco State College education librarian; Lorraine Mathies, University of California at Los Angeles education and psychology library; Rose Marie Service, University of Oregon social science librarian; and Hilmar Sieving, University of Chicago education library.

Others wishing to be active participants should get in touch with Mrs. Marks, if possible before the ALA conference.

Arrangements have been made for all registrants at the 1968 ALA annual conference to be supplied with seventy-two personal, addressed, pressure-sensitive mailing labels, free of charge. These labels are for their convenience in requesting literature from exhibitors, mailing packages home from the accommodations desk and other tasks.

Those who preregister for the annual conference can pick up their supply of labels at exhibit booth No. 2101, which is located just to the left of the main entrance to the Arena of the Municipal Auditorium in Kansas City. Other registrants, who do not preregister, should first fill out a request card procured from

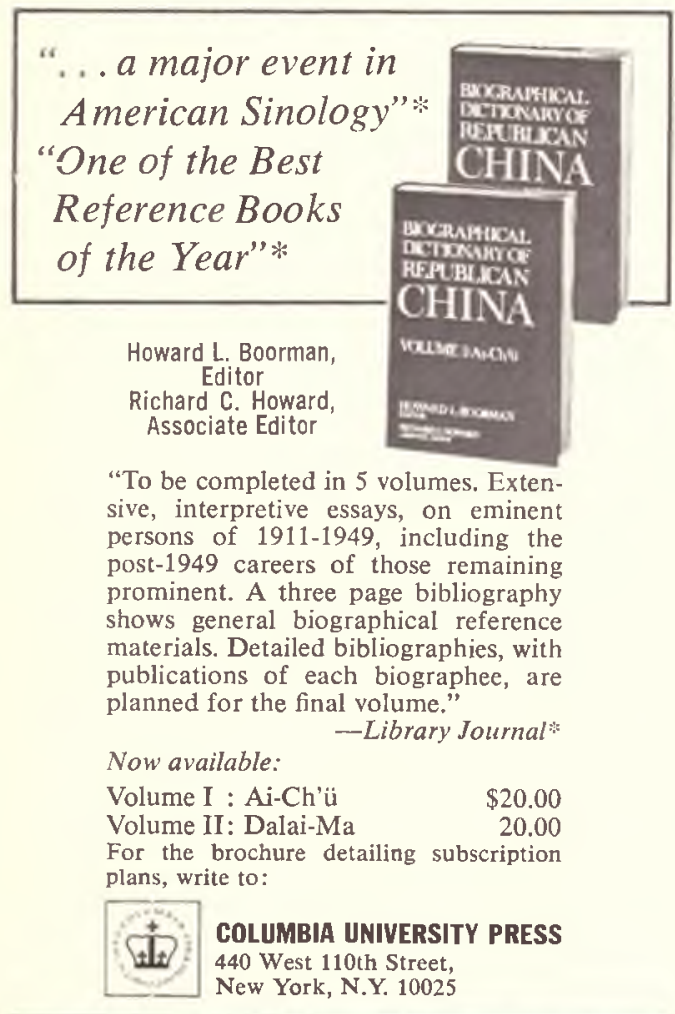

the ALA Registration Desk and take it to the exhibit booth No. 2101 to pick up labels.

The labels, called Avery Tabulabels, are produced in conjunction with the Suffolk (New York) Cooperative Library System and are supplied without cost through the courtesy of the Avery Label Company and UNIVAC Data Processing Division, Remington Rand.

\section{LIBRARY BILL OF RIGHTS}

The Library Bill of Rights, as revised in June 1967, is now available in a size suitable for framing. The ALA Office for Intellectual Freedom has arranged for the production of the enlarged, parchment copy. This attractive item is designed to be used with the standard $16^{\prime \prime}$ by $20^{\prime \prime}$ mat, with $11^{\prime \prime} \times 14^{\prime \prime}$ opening. The standard mat is available at art stores and can be fitted into a standard $16^{\prime \prime}$ by $20^{\prime \prime}$ frame.

The enlarged Library Bill of Rights costs $\$ 1.00$ each, prepaid. Orders should be sent to the Office for Intellectual Freedom, American Library Association, 50 East Huron Street, Chicago 60611.

The smaller version of the Library Bill of Rights document, $8^{\prime \prime} \times 10^{\prime \prime}$ in size, also on parchment, is available, and can be ordered from the same address. Prices for the smaller version are: 100 or less-\$2.50; Additional 100 's- $\$ 2.00$. 500- $\$ 10.00$; Additional 100 's$\$ 1.75$. $1000-\$ 17.50$; Additional 100 's- $\$ 1.50$.

\section{MINNESOTA FACULTY JCLS}

George M. Bailey, executive secretary of ACRL, participated in the annual conference at the Minnesota Junior College Faculty Association, speaking on ALA Programs and Plans, and emphasized the many activities which have developed out of the ten point program proposed by the Joint Committee of ALA and the American Association of Junior Colleges in 1965. Louis Shores discussed the curriculum of the Library Technology Program which he is designing for Texas junior colleges. Wesley Simonton described the ERIC Program for Library and Information Science at the University of Minnesota, and B. Lamar Johnson discussed Library-Centered Innovative Projects Across the Country.

The Librarians Section of the Minnesota Junior College Faculty Association was renamed the "Media Specialists Section." Consideration was given to the possibility of establishing centralized acquisitions and processing for the junior college libraries of Minnesota. Plans are also being made to secure the services of a consultant for junior college libraries, under the sponsorship of the State Junior College Board. 